\title{
Dielectric Characterization and Conduction Modelling of a Water Tree Degraded LDPE
}

\author{
M. Acedo, F. Frutos \\ Universidad de Sevilla \\ Departamento de Física Aplicada 1, ETS Ingeniería Informática, Avda. Reina Mercedes s/n \\ 41012 Sevilla, Spain \\ I. Radu \\ Ecole Polytechnique de Montréal \\ 2900 Boul. Edouard-Montpetit, C.P. 6079, Succ. Centre-Ville \\ Montréal, Québec, H3C 3A7, Canada \\ and J.C. Filippini \\ Laboratoire d'Electrostatique et Matériaux Diélectriques de Grenoble, CNRS-UJF \\ 25 Avenue des Martyrs, B.P. 166 \\ 38042 Grenoble, France
}

\begin{abstract}
Distribution of electric energy by extruded polymer insulated cables continues to be a subject of outstanding relevance in modern industrialized countries all over the world. Dielectric characterization, conduction modelling and finally diagnostics of polymeric insulations are necessary steps towards the development of reliable and less expensive robust technologies of electric power distribution. This paper is devoted to a detailed experimental / theoretical study of the conductive properties of LDPE affected by different levels of degradation by water trees. Water tree layers of different lengths were grown in accelerated conditions and were characterized by water tree kinetics, time-dependent permittivity and polarization current. The polarization current was found to obey a Curie-von Schweidler law whose parameters were used to characterize the effect of ageing time. A new conduction model that takes into account dipole interactions and was obtained from a two-wells Debye model is presented which allows us to give an interpretation of the effect of ageing. This laboratory study was intended to improve the characterization of service power cables aged by water trees.
\end{abstract}

Index Terms - Polarization current, conduction model, water treeing, accelerated ageing, permittivity, low density polyethylene.

\section{INTRODUCTION}

ONE of the most important applications of polymer dielectrics (EPR, HDPE, XLPE, LDPE...) is their extended use as power cable insulations. The typical degradation known as water treeing usually appears in underground / submarine cables and it is mainly due to electrical stress and humidity in wet environment. That is why industries of PE production and fabrication of cables as well as utilities for energy distribution are very interested in the study of water trees. Their existence has been known for the last thirty years (for reviews, see $[1,2])$. Water trees are small-damaged zones that can appear in polymeric insulations of ac medium and high voltage (MV, HV) cables $[3,4]$. They frequently look like bushes or trees and improved optical microscopy techniques permitted to conclude that every water tree is made up of "bouquets", which are alignments of microcavities [5]. Water trees grow during the service life of power cables from defects where the electric field is amplified $[3,4,6,7,8]$. The longer the water tree, the more dangerous it becomes, because the insulation breakdown voltage decreases with the increase of the length of water trees $[4,9,10]$.

Another very important phenomenon in power cables affected by water trees is the conduction process. This is also of great interest for both users and manufacturers of cables $[4,11,12,13]$ because electrical conduction is one of the factors that reveal the level of degradation of the cable. Concerning the polymer conductivity, the study of the mechanisms of thermo-electrical degradation of the polyethylene insulation is essential in order to develop improved assessment strategies [14]. Although many works have been devoted to the development and review of diagnostic methods of $\mathrm{MV} / \mathrm{HV}$ 
power cables affected by thermal ageing or degradation in the presence of water $[15,16,17,4]$ in the last few years, a thorough theoretical / experimental study of the conduction processes is necessary for developing new diagnostic technologies. They should serve both for new extra high voltage (EHV) cables as well as for old-in-service cables which is of outstanding importance because utilities must ensure reliability of their present distribution systems without making unnecessary huge investments.

"Macroscopic" modelling of conduction processes can be done by considering the dielectric function response $([18,19$, $20,21]$ of the polymer. Nevertheless, in order to have a deeper look into material, we were interested in developing a "microscopic" modelling of conduction in PE. Hence, on the basis of a previously published Debye-like model [22] and taking into account the idea of dipole interaction from the 'Many Body Universal Model of Dielectric Relaxation' [23,24,25], we propose a new conduction model for water tree degraded LDPE that reproduces the Curie-von Schweidler potential dependence of real current measurements and permits an easy physical interpretation of their fitting parameters. Consequently, in this article, we characterize the conduction processes in new and aged polyethylene by using experimental results and we present a new theoretical model for the conduction processes.

Water treeing was produced in laboratory material specimens and not in cables although our experimental test objects (LEMD-CNRS) simulate very closely this degradation process in real cables. Accordingly, in the beginning of our paper we describe the experimental procedures for the growth and characterization of water trees and the electrical measurement techniques. Afterwards, we present the experimental results for the water tree kinetics, electrical capacitance / permittivity evolution and current measurements, especially using specimens with different degrees of treeing. A special attention was paid to ensure high levels of repeatability and reproducibility, and to prevent any type of artifacts and parasitic effects in all the experimental procedures used. We then present our new electrical conduction model that takes into account both the current time dependence and the evolution of water trees and give an interpretation of the experimental results. Finally, using the simulation results from our model, we discuss the correlation between both the degree of ageing / level of polarization voltage, and the evolution of the fitting parameters of current experimental data to the potential Curie-von Schweidler law.

\section{EXPERIMENTAL}

Plane-plane LDPE specimens were obtained from sheets prepared with a "Carver" heating press at LEMD-CNRS. A precise method for the fabrication of those sheets was developed which allowed us to cut disks of great homogeneity whose thickness/diameter were respectively $\mathrm{L} \cong 500 \mu \mathrm{m}$ ( $\Delta \mathrm{L} \cong 10 \mu \mathrm{m}$ ) and $\Phi=35 \mathrm{~mm}$. A granulated mass of LDPE (base polyethylene for compounds for cable insulation with antioxidants and stabilizers from Borealis), $\mathrm{m}=1 \mathrm{~g}$, was inserted in each of the 12 circular holes of a brass matrix and exposed to successively selected conditions of pressure, temperature and waiting periods. In this way we could attain the necessary homogeneity and quasi-uniform width in our experimental specimens for ensuring a good (i) repeatability / (ii) reproducibility in electric measurements which are defined as: (i) quality in the repetition (iteration) of a measurement on a unique specimen; (ii) quality in the repetition of a measurement on several specimens -identical specimens in principle-. From the point of view of accelerated ageing, the typical degradation of cable polymeric insulations known as "water treeing" was simulated at laboratory using a planeplane electrode configuration, a $0.1 \mathrm{M} \mathrm{NaCl}$ solution and an ageing voltage of $5 \mathrm{kV}_{\text {rms }}$ at $1500 \mathrm{~Hz}$. Once the laboratory specimens were assembled from disks, and previously to the measurement of polarization current with a Keithley $6517 \mathrm{~A}$ electrometer, $\mathrm{I}(\mathrm{t})$, the evolution of capacitance, $\mathrm{C}$, and dielectric losses, $\tan \delta$, $[4,10]$ was also controlled for the same scheduled periods of accelerated ageing. In parallel with these experiences, a destructive microscopic analysis of the water tree aged specimens was also performed, which allowed us (once the water tree kinetics for the LDPE under study was completed) to establish a continued correlation between the evolution of the above electrical variables and the actual treed thickness. Such a correlation permits the usage of the related variables as an instrument of degradation diagnosis for any specimen under test. The description of the samples used in non-destructive measurements of polarization current, capacitance and dielectric losses is summarized in Table 1. All the measurements were taken at room temperature.

Table 1. Summary of accelerated ageing conditions and elementary samples characteristics (thickness, L, and capacitance, C) for samples series K, M and $\mathrm{J}$ used in non-destructive measurements.

\begin{tabular}{|l|l|l|}
\hline \multicolumn{3}{|l|}{ AGEING CONDITIONS:................. $=5 \mathrm{kV}_{\mathrm{rms}} ; \mathrm{f}=1500 \mathrm{~Hz}$} \\
\hline \multicolumn{2}{|l|}{ SAMPLES CHARACTERISTICS $\ldots \ldots \ldots \ldots\{(\mathrm{L}[\mu \mathrm{m}], \Delta \mathrm{L}[\mu \mathrm{m}]) ; \mathrm{C}[\mathrm{pF}]\}$} \\
\hline Series K (for $\left.\mathrm{t}_{\mathrm{ag}}=0 \mathrm{~h}\right)$ & \multicolumn{1}{|l|}{ Series M $\left(\mathrm{t}_{\mathrm{ag}}=0 \mathrm{~h}\right)$} & Series J $\left(\mathrm{t}_{\mathrm{ag}}=202 \mathrm{~h}\right)$ \\
\hline $\mathrm{K} 4:(534,10) ; 13.0$ & $\mathrm{M} 1:(530,0) ; 12.9$ & $\mathrm{~J} 1:(514,10) ; 17.4$ \\
\hline $\mathrm{K} 5:(534,10) ; 13.0$ & $\mathrm{M} 2:(532,10) ; 12.6$ & $\mathrm{~J} 3:(514,10) ; 17.2$ \\
\hline $\mathrm{K} 6:(534,10) ; 13.0$ & $\mathrm{M} 3:(532,10) ; 12.9$ & $\mathrm{~J} 4:(518,10) ; 17.2$ \\
\hline $\mathrm{K} 7:(530,10) ; 12.7$ & $\mathrm{M} 4:(528,10) ; 12.8$ & $\mathrm{~J} 5:(520,0) ; 18.8$ \\
\hline $\mathrm{K} 9:(528,10) ; 13.0$ & $\mathrm{M} 5:(524,10) ; 13.1$ & $\mathrm{~J} 6:(520,0) ; 16.9$ \\
\hline
\end{tabular}

\subsection{GROWTH AND CHARACTERIZATION OF WATER TREES}

In order to obtain a multitude of water trees we produced a wide dispersion of tree inception points in one of the sides of the cutted disks of LDPE. We applied a pressure of 372 bar, during an interval of 2 min with an abrasive paper P400 (used and replaced after its application) and we repeated this process twice for each disk $[4,26]$. This abrasive-paper method, at least in LDPE, revealed as less aggressive and more reproducible than the method of sandblasting [27], especially because we could choose a grain width which produces a kind of defect deep enough for initiating water trees without involving a direct risk of dielectric breakdown when applying the ageing voltage. The laboratory specimens $[4,10]$ (see Figure 1) were placed on a metallic recipient, which acted both as ground electrode and as a container of a small quantity of silicone oil. 


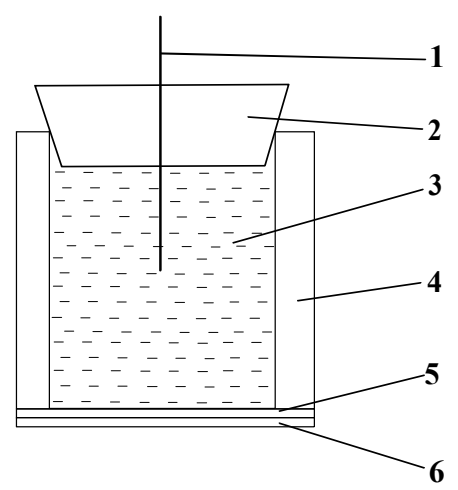

Figure 1. Specimen configuration: (1) platinum electrode, (2) silicon cap, (3) salt solution, (4) PE cylinder, (5) LDPE disk, (6) silver paint.

It helps to avoid partial discharges in the air by filling the occasional small cavities that usually appear between the LDPE disk and the metallic plane of the ground electrode. We got several very important advantages from the usage of the oil technique. (a) There is a drastic diminution of the risk of dielectric breakdown for short ageing periods for thin layers of water trees. It means not only a reduction in the number of lost test objects but the fact that the process of tree growth for the rest of specimens is much more continued and reliable, as water tree retractions attributed to periods of absence of applied electric field are mainly avoided [28]. (b) The possibility of applying a stronger ageing electric field $\left(E_{\text {oiled }} \cong 10 \mathrm{kV} / \mathrm{mm}\right.$ vs $E_{\text {non-oiled }} \cong 3 \mathrm{kV} / \mathrm{mm}$ ). Consequently, deeper and thicker degraded layers are developed for much shorter ageing periods. It permits us their detection through very significant changes for the values of electrical variables in measurements $\{\mathrm{C}, \mathrm{I}(\mathrm{t}), \tan \delta\}$. Once the ageing period is finished, the active part of the test object (LDPE disk with water trees) is extracted and stained with rodhamine during 48 $\mathrm{h}$ at a temperature of $60^{\circ} \mathrm{C}$. Afterwards, five $200 \mu \mathrm{m}$ width slices are cut from each disk with a microtome and their coloured water trees can already be visualized by using an optical microscope. Water tree average length was determined for each scheduled ageing time from equation (1),

$$
l_{w}=\frac{\sum_{i=1}^{N} l_{i} x_{i}}{x_{\max }}
$$

Where $l_{i}$ and $x_{i}$ are respectively the length and width of each individual water tree, $\mathrm{N}$ is the total number of trees per slice and $\mathrm{x}_{\max }$ is the total length of each slice.

\subsection{EXPERIMENTAL PROCEDURES FOR ELECTRIC MEASUREMENTS}

\subsubsection{POLARIZATION CURRENT TECHNIQUE}

The LEMD experimental set-up for polarization current measurement is shown in Figure 2. Current measurement and DC stabilized voltage supply were both performed by using a Keithley 6517A. Data acquisition was done by means of a

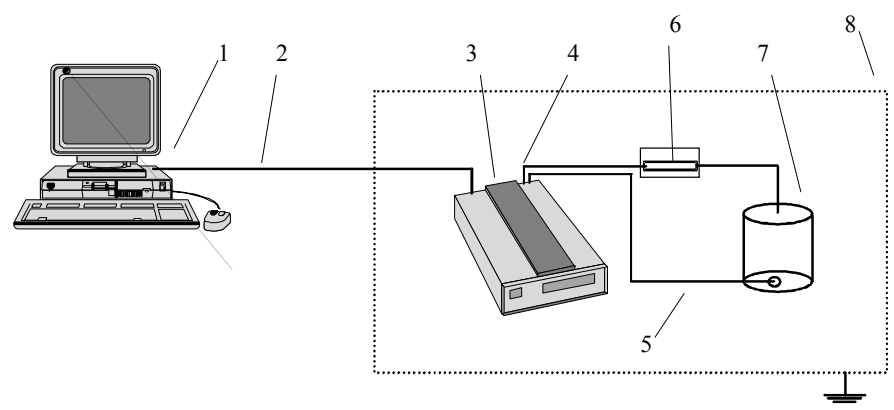

Figure 2. Experimental set-up for current measurements: (1) IEEE-488 card inserted in a PC586, (2) GPIB cable, (3) ammeter (Keithley 6517A), (4) stabilized DC source (Keithley 6517A), (5) triaxial connections, (6) protection resistance, (7) specially designed test cell, (8) continuous copper Faraday cage.

software developed from Keithley Testpoint packet. A special goal for this kind of very low current measurements consists in minimizing noise. Electromagnetic noise could be reduced by providing an especially designed test cell, triaxial connections between Keithley and test cell, a metal box for the protection resistance and an additional continuous copper Faraday cage which confined all the previous elements. The physical components of the test cell are schematically drawn in Figure

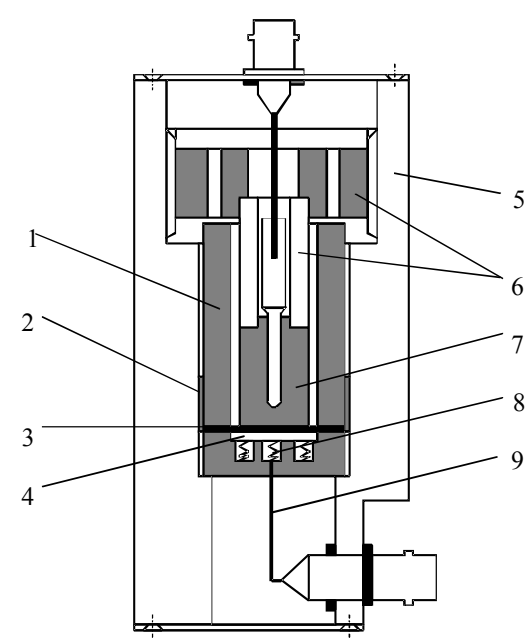

Figure 3. Test cell: (1) PE cylinder, (2) guard ring, (3) LDPE sample, (4) lower electrode, (5) protective screen, (6) PTFE insulator, (7) upper electrode, (8) contact spring, (9) copper wire.

3. A special attention must be paid to the design of its upper electrode which must make contact at a very well defined area on every LDPE specimen. A first screwed version of this upper electrode was substituted by a more weighted one whose contact was simply done by its weight. In this way, repeatability and reproducibility were greatly improved because of the constant pressure at the contact and by avoiding the possible generation of charges by a kind of mechanical stirring on the surface of the polymer [29]. Analytical/graphical processing of experimental data was performed with Kaleidagraph 3.07 and Sigmaplot 5.0 programs. 


\subsubsection{CAPACITANCE MEASUREMENTS}

An IRLAB apparatus (model LDTRP-2) and a 1621 General Radio bridge successively switched to the specially designed cell mentioned above were used to get the values of capacitance, $\mathrm{C}$, and dissipation factor, $\tan \delta$, for every scheduled ageing period.

\subsubsection{PARASITIC EFFECTS}

Before each measurement, the salt solution is removed and the rest of solution on the sample surface is eliminated by a process of absorption with absorption paper [4]. Nevertheless we observed that solution continues to evaporate from the sample at room temperature for about 20 minutes, which is proved by a continuous diminution of its capacitance and dielectric losses factor. Consequently, after absorption, a waiting period, $\mathrm{t}_{\mathrm{dry}} \cong 20 \mathrm{~min}$, is absolutely required for avoiding variations in capacitance (and in the rest of electrical variables) with time -particularly in thick treed layers-. Then, when this period is over, we consider that the measured capacitance is representative both of polyethylene and the water tree with its water. Concerning polarization current measurements, residual currents can be measured in the absence of applied polarization voltage, $\mathrm{V}_{\mathrm{DC}}$, when the ageing period is over. They can endure for periods ranging from 10 min up to $1 \mathrm{~h}$ depending on the LDPE volume affected by water trees. An adequate method for minimizing these residual currents was applied by short-circuiting the entire test object support -once the ageing period is finished-during a period of about, $\mathrm{t}_{\text {shor }} \cong 30 \mathrm{~min}$.

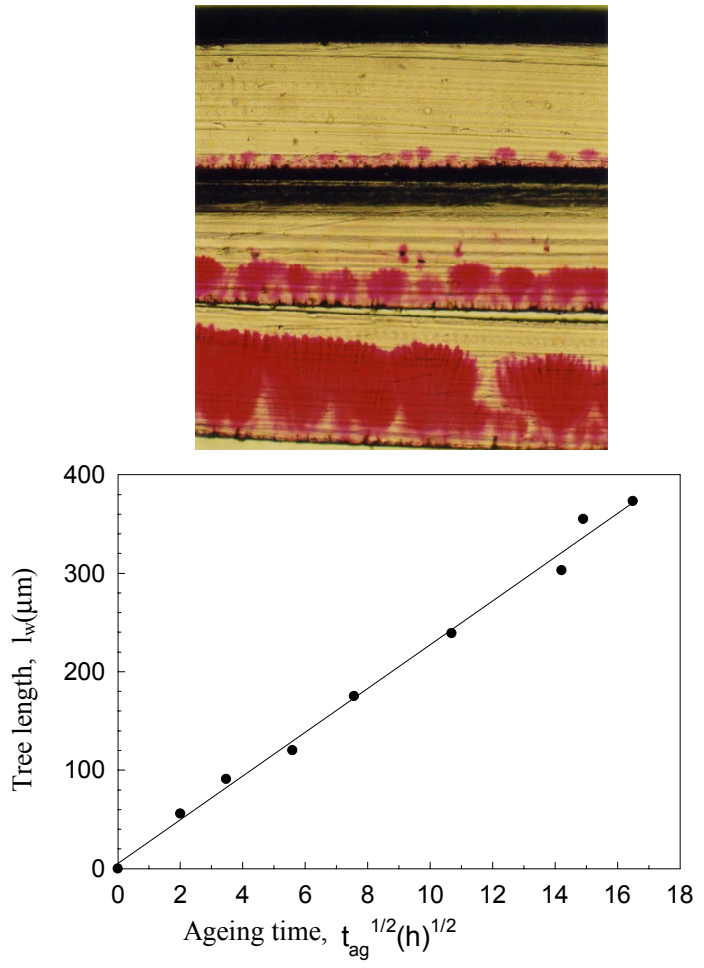

(a)

(b)

Figure 4. Water tree evolution in LDPE under accelerated conditions -ageing voltage of $5 \mathrm{kV}_{\text {rms }}$ at $1500 \mathrm{~Hz}$ with solution $[\mathrm{NaCl}]=0.1 \mathrm{M}-$ : (a) three photographs taken after ageing times (from top to bottom) of $4 \mathrm{~h}, 31 \mathrm{~h}$ and $272 \mathrm{~h}$; (b) average water tree length dependence on ageing time, $1_{\mathrm{w}}$ versus $\mathrm{t}_{\mathrm{ag}}{ }^{1 / 2}$.

\section{EXPERIMENTAL RESULTS}

\subsection{THE GROWTH KINETICS AND THE CAPACITANCE OF WATER TREES}

In parallel with the non-destructive measurements of capacitance and current within our experimental procedures, we also undertook destructive measurements in order to obtain the thickness of tree degraded polymer - water tree length $1_{\mathrm{w}}-$ for different ageing periods as we explained in section 2.1.

Destructive measurements are necessary for two main reasons : firstly they enable us to establish a continued correlation between electrical variables (current / capacitance) and degradation thickness which represents a diagnostic purpose and secondly and most important, water tree length measurements are necessary to evaluate water tree permittivity [30] which is essential for mathematical simulations from our new proposed conduction model.

The evolution of water trees with the ageing time in a LDPE sample is shown both graphically with pictures and from the variations of the average water tree length -water tree kinetics- in Figure 4.

From Figure $4 \mathrm{~b}$ we conclude that the water tree length varies very approximately with ageing time as $t_{a g}{ }^{1 / 2}$, in agreement with the very recent theoretical model published by Crine and Jow [31].

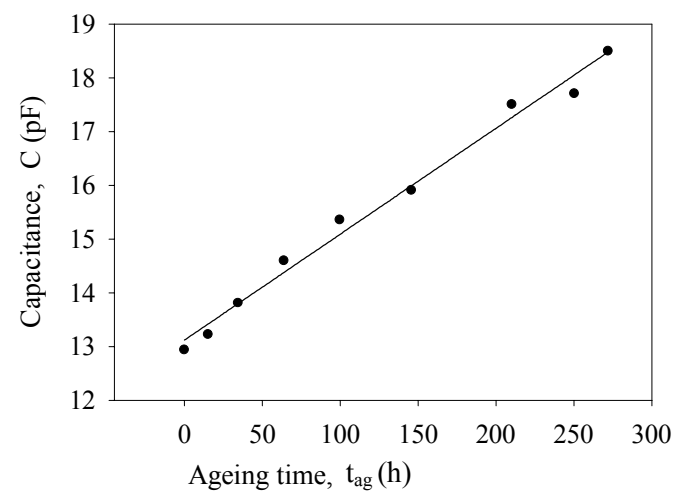

Figure 5. Average electric capacitance as a function of ageing time.

Otherwise, a quasi-linear dependence for the variations of the average capacitance of the samples with the ageing time was also obtained from direct measurements (Series K). This result is plotted in Figure 5.

Using an equivalent plane capacitor model for the water treed samples and taking into account the variations of capacitance, $\mathrm{C}$, and water tree length, $1_{\mathrm{w}}$, with the ageing time, $t_{\mathrm{ag}}$, the average relative permittivity of water trees, $\varepsilon_{1}$, can be derived from,

$$
\varepsilon_{1}(t)=\frac{C\left(t_{a g}\right) \varepsilon_{2} l_{w}\left(t_{a g}\right)}{l_{w}\left(t_{a g}\right) C\left(t_{a g}\right)-L\left[C\left(t_{a g}\right)-C_{i}\right]}
$$

where $\varepsilon_{2}=2.3$ is the relative permittivity of non-degraded PE and $\mathrm{C}_{\mathrm{i}}$ is the non-degraded capacitance of the sample. A maximum value, $\varepsilon_{1 \max }=4$. 1 , was attained. 


\subsection{CURRENT MEASUREMENTS}

\subsubsection{EVOLUTION OF I(t) WITH DEGRADATION}

Figure 6 shows the polarization current experimental data for a measuring period of $10 \mathrm{~min}$, a polarization voltage $\mathrm{V}_{\mathrm{DC}}=300 \mathrm{~V}$ and different periods of accelerated ageing. The experimental data were fitted to the potential Curie-von Schweidler law, $\mathrm{I}=\mathrm{I}_{0} \mathrm{t}^{-\mathrm{m}}$. Their corresponding parameters $\left\{\mathrm{I}_{0}, \mathrm{~m}\right\}$ and degraded width percentage, $\mathrm{g}(\%)=\left(1_{\mathrm{w}} / \mathrm{L}\right) \cdot 100$, were summarized in Table 2. We can obtain a first version of diagnostic method -estimation of the degree of degradation from a unique $I(t)$ measurement- by simply plotting and adjusting the dependence $\mathrm{g}=\mathrm{g}(\mathrm{m})$, which is shown in Figure 7.

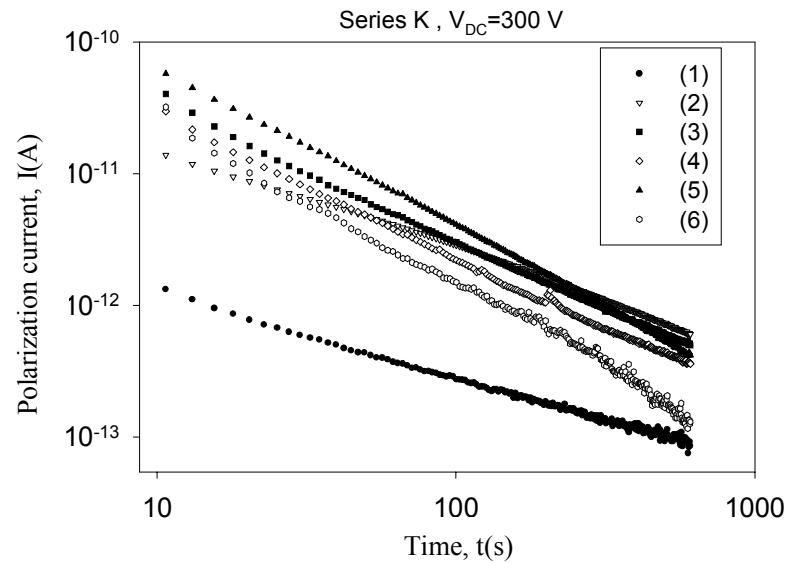

Figure 6. Polarization current measurements for different water tree ageing periods and a polarization voltage of $\mathrm{V}_{\mathrm{DC}}=300 \mathrm{~V}$ (averaged values from samples of Series K): (1) 0h, (2) 15h, (3) 34 h, (4) 64 h, (5) 146 h, (6) $250 \mathrm{~h}$.

Table 2. Fitting parameters $\left\{\mathrm{I}_{0}, \mathrm{~m}\right\}$ for each ageing time and corresponding degraded width percentage.

\begin{tabular}{|c|c|c|c|}
\hline $\mathbf{t}_{\mathbf{a g}}(\mathbf{h})$ & $\mathbf{g}(\mathbf{\%})$ & $\mathbf{I}_{\mathbf{0}}(\mathbf{A})$ & $\mathbf{m}$ \\
\hline 0 & 0 & $6.251 \cdot 10^{-12}$ & 0.666 \\
\hline 15 & 14.8 & $1.1477 \cdot 10^{-10}$ & 0.8106 \\
\hline 34 & 22.3 & $4.1352 \cdot 10^{-10}$ & 1.0566 \\
\hline 64 & 34 & $3.5889 \cdot 10^{-10}$ & 1.0893 \\
\hline 146 & 56.3 & $1.2905 \cdot 10^{-9}$ & 1.2491 \\
\hline 250 & 70.7 & $6.1215 \cdot 10^{-10}$ & 1.3001 \\
\hline
\end{tabular}

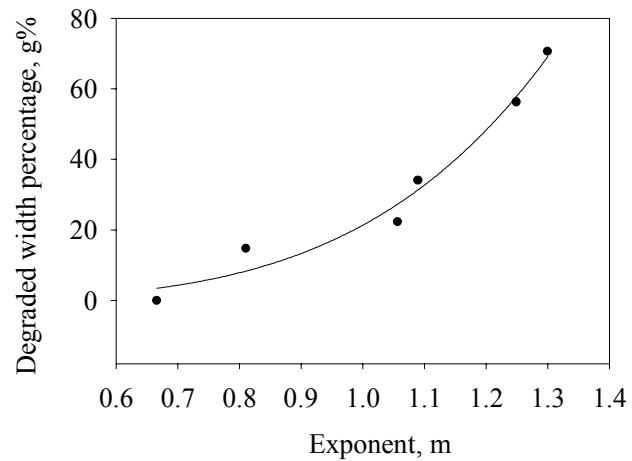

Figure 7. The dependence $\mathrm{g}=\mathrm{g}(\mathrm{m})$ as a first version of diagnostic tool for LDPE treed samples.

\subsubsection{EVOLUTION OF I(t) WITH POLARIZATION VOLTAGE}

Figure 8 shows the polarization current measurements in aged samples (Series $\mathrm{J}$ ) as a function of the polarization voltage, $V_{\text {DC }}$. A similar study was performed for new samples
(Series $\mathrm{M}$ ) and their corresponding fitting parameters $\left\{\mathrm{I}_{0}, \mathrm{~m}\right\}$ are summarized in Table 3. A prevailing trend to saturation in the evolution of exponent $m$ with polarization voltage, $V_{D C}$, for both aged (decreasing variation) and new (increasing variation) LDPE samples is observed and depicted in Figure 9. Consequently, a second tool of degradation diagnosis for this kind of test objects could be developed on the basis of the variations of exponent $\mathrm{m}$ as a function of the polarization voltage level.

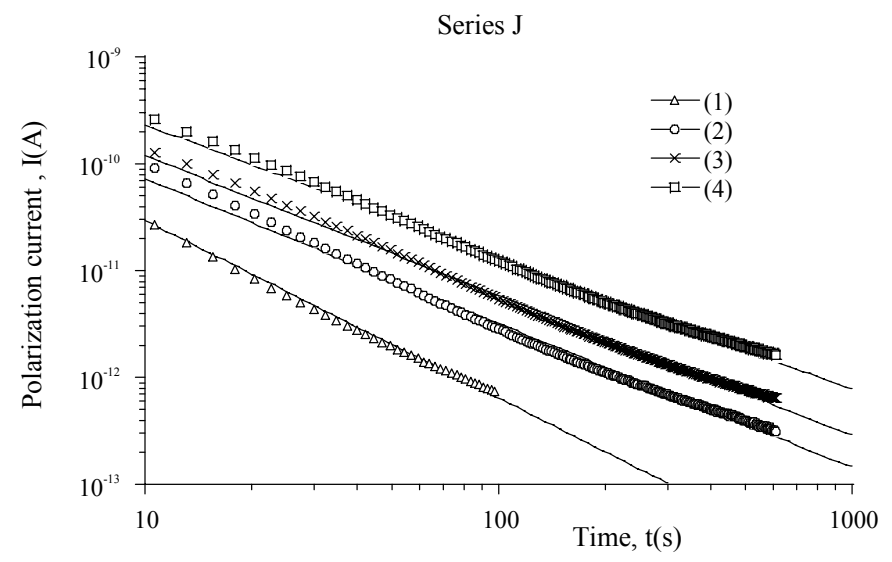

Figure 8. Polarization current measurements and their linear curve fitting for different values of the polarization voltage, $\mathrm{V}_{\mathrm{DC}}$ (averaged values from aged samples of Series J with degraded width percentage, $g=63 \%$ ): (1) $100 \mathrm{~V}$, (2) $300 \mathrm{~V}$, (3) $500 \mathrm{~V}$, (4) $1000 \mathrm{~V}$.

Table 3. Polarization current fitting parameters $\left\{\mathrm{I}_{0}, \mathrm{~m}\right\}$ for new samples (Series M) and aged samples (Series $J$ ) as a function of $\mathrm{V}_{\mathrm{DC}}$.

\begin{tabular}{|l|l|l|l|l|}
\hline $\mathbf{V}_{\text {DC }}(\mathbf{V})$ & \multicolumn{2}{|c|}{$\mathbf{I}_{\mathbf{0}}(\mathbf{A})$} & \multicolumn{2}{c|}{ m } \\
\hline & Series M & Series J & Series M & Series J \\
\hline 100 & $4.7826 \cdot 10^{-13}$ & $1.3465 \cdot 10^{-9}$ & 0.42736 & 1.6603 \\
\hline 300 & $2.5357 \cdot 10^{-12}$ & $1.6406 \cdot 10^{-9}$ & 0.61002 & 1.3546 \\
\hline 500 & $4.0321 \cdot 10^{-12}$ & $2.4369 \cdot 10^{-9}$ & 0.63351 & 1.3102 \\
\hline 1000 & $1.0702 \cdot 10^{-11}$ & $4.0661 \cdot 10^{-9}$ & 0.69758 & 1.2419 \\
\hline
\end{tabular}

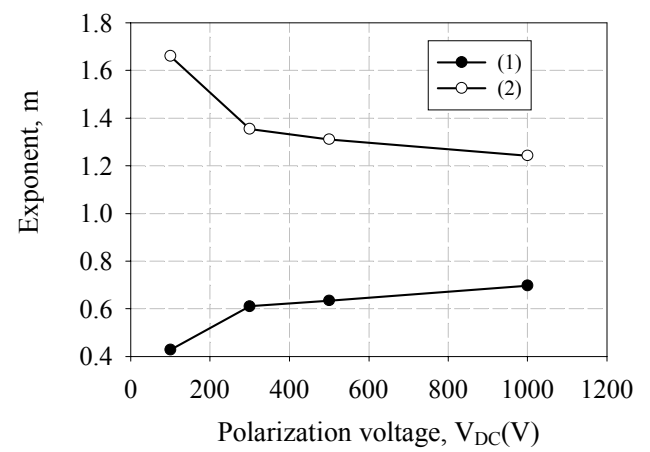

Figure 9. Detail of the tendency to saturation in the evolution of the exponent $\mathrm{m}$ in new (1) and aged (2) LDPE samples as a function of polarization voltage.

\section{CONDUCTION PROCESS MODELLING}

A Debye-type conduction model based on the dielectric relaxation of independent dipoles for polyethylene was presented in [22]. A more realistic new approach to the modelling of these processes is proposed in this work [32]. It is based on the assumption of interaction between dipoles following the "Many-Body Universal Model of Dielectric 
Relaxation" $[23,24,25]$. We have tried to validate the proposed model in a LDPE affected by different levels of water tree degradation. The model is founded on several hypotheses: one of them takes as a basis the variations of permittivity with the degree of water treeing damage and others take into account the microscopic structure of the material. With these simplifying hypotheses the proposed model can account for the larger part of our experimental results. The application of the "Many Body Universal Model of Dielectric Relaxation" implies that for a long enough measuring time, a "slow down" process in polarization is activated: it is due to the mechanism of local redistribution of energy (flip-flop transitions) which results in a power dependence for polarization current, with a negative exponent whose absolute value is $m \in(0,2)$. Because of the mathematical complexity of this theory, we propose in this paper a modification of the model of non-interacting dipoles presented in [22], in order to take into account interactions. With the aid of the new model we have tried to explain the variations of parameters in the power current law (best-fitted dependence for the polarization current measurements) as a function of (a) the degree of degradation by water trees and (b) the polarization voltage. Finally, a discussion about the validation of the model and its range of applicability is performed.

\subsection{MODEL}

\subsubsection{TWO POTENTIAL WELL MODEL}

The mechanism of dipole orientation is often considered as responsible for polarization currents in solid dielectrics. Nevertheless, in a dielectric material in which no important dipolar groups are present, polarization currents could be attributed to ion jumps between equilibrium nearby-positions. Both mechanisms can be explained by means of a unique simplified model in which a charged particle can jump between two close positions separated by a potential energy barrier -two potential well (Figure 10)- [23,33]. For this

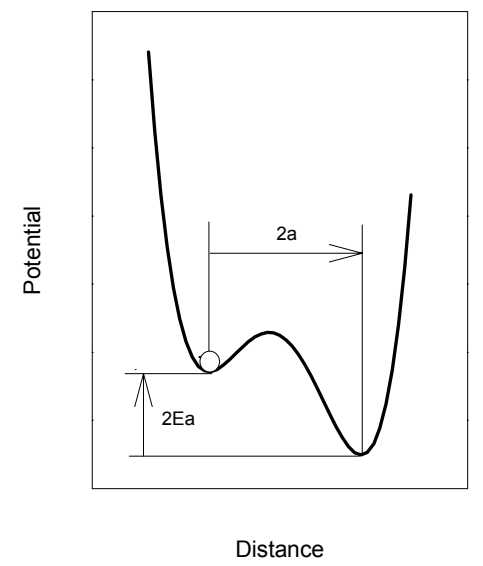

Figure 10. Elementary scheme of two potential well model: E, applied electric field; $2 \mathrm{a}$, distance between two well sites.

model and considering a plane-plane sample for relatively low applied electric fields, the variation of local polarization $\mathrm{P}$ with time is given by,

$$
\frac{\partial P(x, t)}{\partial t}=-\alpha P(x, t)+\frac{\alpha b(x)}{k_{B} T} E(x, t)
$$

where $\mathrm{E}(\mathrm{x}, \mathrm{t})$ is the electric field, $\alpha$ is the probability per unit time that one ion changes its equilibrium position in the absence of applied electric field and due to the thermal energy,

$$
\alpha=2 v \exp \left(-\frac{W}{k_{B} T}\right)
$$

where $v$ is the vibration frequency of ions inside their wells, $\mathrm{W}$ is the height of the potential energy barrier which separates the two respective well sites and $\mathrm{b}(\mathrm{x})$ is given by,

$$
b(x)=p^{2} n(x)
$$

where the concentration of ions is represented by $\mathrm{n}(\mathrm{x})$ and the dipolar moment associated to one ion is represented by $\mathrm{p}$. From (3) and considering that the contribution of ohmic conduction is irrelevant, we get a simplified expression for the current density,

$$
J(t)=\varepsilon_{0} \frac{\partial E(x, t)}{\partial t}+\frac{\partial P(x, t)}{\partial t}
$$

We will study the dielectric response to a step voltage given by,

$$
V(t)=V_{D C} \cdot u(t)
$$

\subsubsection{ALTERNATIVE APPROACH FOR DIPOLE INTERACTIONS}

Due to the difficulty for the interpretation of the physical meaning in the coefficients of the power current response supplied by the "Many Body" theory -especially from an experimental/applied point of view-, we propose a simplified alternative approach: departing from the non-interacting dipoles model (mathematical equations, numerical calculations and simulations developed in [22]), we introduce a simple mathematical algorithm that accounts for dipole interactions. This new model also predicts a power current law for the response of the dielectric material (similar dependence of the experimental Curie-von Schweidler law, $\left.\mathrm{I}(\mathrm{t})=\mathrm{I}_{0} \mathrm{t}^{-\mathrm{m}}\right)$ but this time, coefficients $\left\{\mathrm{I}_{0}, \mathrm{~m}\right\}$ can be readily determined as easy functions of the microscopic/macroscopic parameters of the material. Dipole interactions will be described by an "effective" potential energy barrier, which grows with the measuring time $t$ as,

$$
W(t)=W_{0}+\Delta W(t)
$$

where $\mathrm{W}_{0}$ is the potential energy barrier of the non-interacting dipoles model. Consequently, it implies that parameter $\alpha$ of the new model must depend on time $t$. Such a time dependence must be a decreasing one and its initial value must coincide 
with that of the non-interacting model, $\alpha_{0}$. We propose next expression for $\alpha(t)$,

$$
\alpha(t)=\frac{\alpha_{0}}{1+\frac{t}{\tau}}
$$

\subsection{HOMOGENEOUS MATERIAL}

In the case of a homogeneous material, all the variables in equation (3) are independent from position, x. Furthermore, for $\mathrm{t}>0$ electric field is independent from time and is given by $\mathrm{E}=\mathrm{V}_{\mathrm{DC}} / \mathrm{L}$, then equation (3) becomes,

$$
\frac{d P(t)}{d t}=-\alpha(t)\left(P(t)-P_{S}\right)
$$

where,

$$
P_{S}=\frac{b V_{D C}}{k_{B} T L}
$$

By integration of (10) and making use of equations (9) and (6) we get,

$$
J(t)=\frac{V_{D C}}{L} \varepsilon_{o} \delta(t)+\alpha_{o} P_{S}\left(1+\frac{t}{\tau}\right)^{-\alpha_{o} \tau-1}
$$

Finally, if $\mathrm{t}>>\tau$, current is

$$
I(t)=I_{o} t^{-m}
$$

where,

$$
\begin{aligned}
& \text { (i) } m=1+\alpha_{o} \tau=1+2 \nu \tau \exp \left(-\frac{W_{0}}{k_{B} T}\right) \\
& \text { (ii) } I_{o}=S \alpha_{o} P_{S} \tau^{m}=S \alpha_{0} \frac{b V_{D C}}{k_{B} T L} \tau^{m}
\end{aligned}
$$

which means that we get expressions that directly connect the microscopic/macroscopic variables of our LDPE sample with the actual values of our measured experimental current parameters $\left\{\mathrm{I}_{0}, \mathrm{~m}\right\}$ [34]. Moreover, we will be able to discuss the evolutions of the parameters (Curie-von Schweidler law) with the variations of polarization voltage and water tree degradation, as we will see later on.

\subsection{INHOMOGENEOUS MATERIAL}

In the case of a water tree degraded LDPE -inhomogeneous material (see schematic drawing in Figure 11)- we cannot obtain, in general, an analytical solution from (3). Consequently we used numerical methods for the calculation and simulation of polarization, $\mathrm{P}(\mathrm{x}, \mathrm{t})$, and polarization current, $I(t)$. The hypotheses used for the numerical calculations are:
1. Parameter $\alpha(t)$ is independent of position, $x$.

2. Parameter $b(x)$ which is related to the permittivity of the material depends on the position as,

$$
b(x)= \begin{cases}b_{\max }-u x, & x \in\left[0, \frac{g}{100} L\right] \\ b_{P E}, & x \in\left(\frac{g}{100} L, L\right]\end{cases}
$$

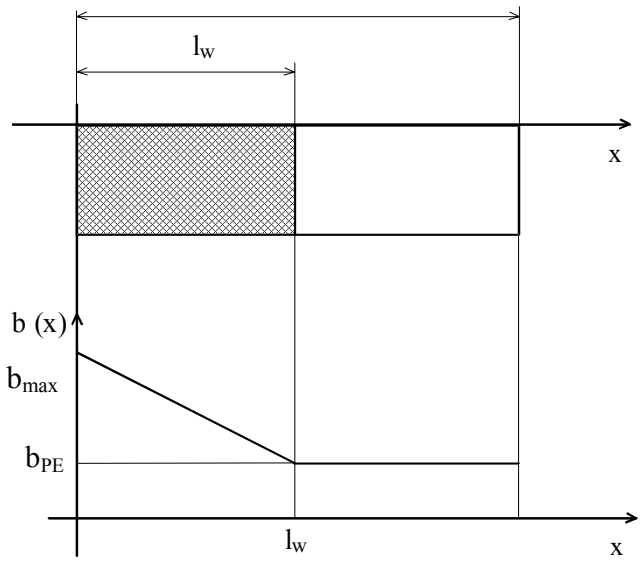

Figure 11. Model for the variation of parameter $b=b(x)$ within the LDPE plane-plane sample from the hypotheses for the variation of permittivity in a water treed specimen $[30,10]: 1_{\mathrm{w}}=\mathrm{gL} / 100 \equiv$ degraded width corresponding to a continuous layer of water trees.

where $g$ represents the percentage value of degraded material, $b_{\max }$ is the value of $b(x)$ that corresponds to a maximum relative permittivity whose actual value was chosen as 4.1 (for $\left.t_{a g}=272 \mathrm{~h}\right), b_{P E}$ is the value of $b$ in the non-degraded region, whose relative permittivity was chosen as 2.3 and $u$ is the slope of the assumed linear dependence. The related permittivity values are taken from real permittivity measurements performed on polyethylene specimens degraded by water trees $[34,4]$. We also took into account for our calculations the relationship between the macroscopic variable relative permittivity, $\varepsilon_{\mathrm{r}}$, and the microscopic parameter $\mathrm{b}=n \mathrm{p}^{2}$,

$$
\varepsilon_{r}(x)=1+\frac{b(x)}{\varepsilon_{0} k_{B} T}
$$

\subsection{SIMULATION RESULTS}

Experimental results are interpreted from the proposed model of interacting dipoles by using equation (13). Nevertheless, for small water-tree degraded layers, an interpretation of the exponent parameter $\mathrm{m}$ of experimental polarization curves is not possible as $m<1$. According to equation (14i), this model can only explain the current curves corresponding to a higher level of degradation which gives experimental exponents $m$ greater than unity $(m>1)$ : i.e. the experimental results of Figure 6 that are related to ageing times: $t_{a g}=34 \mathrm{~h}, 64 \mathrm{~h}, 146 \mathrm{~h}, 250 \mathrm{~h}$. From numerical integration, we can obtain the values of the characteristic microscopic parameters of our conduction modelling $\left(\tau, \alpha_{0}\right.$, 
Table 4. Microscopic parameters from numerical integration $\left(\tau, \alpha_{0}, W_{0}\right)$ as a function of the degree of water tree degradation, $\mathrm{g}$.

\begin{tabular}{|c|c|c|c|}
\hline $\mathbf{g}(\mathbf{\%})$ & $\boldsymbol{\tau} \mathbf{( s )}$ & $\boldsymbol{\alpha}_{\mathbf{0}}\left(\mathbf{s}^{\mathbf{- 1}}\right)$ & $\mathbf{W}_{\mathbf{0}}(\mathbf{e V})$ \\
\hline 22.3 & 0.14 & 0.124 & 0.768 \\
\hline 34 & 0.12 & 0.37 & 0.74 \\
\hline 56.3 & 0.52 & 0.454 & 0.735 \\
\hline 70.7 & 0.27 & 1.0385 & 0.713 \\
\hline
\end{tabular}

$\mathrm{W}_{0}$ ) as a function of the level of degradation in the insulating material, as shown in Table 4. Figure 12 is just an example of the degree of adjustment between the current results $I(t)$, obtained from numerical integration (curve (2)) and from the experimental data (curve (1)) corresponding to a sample of degraded width $\mathrm{g}=70.7 \%\left(\mathrm{t}_{\mathrm{ag}}=250 \mathrm{~h}\right)$. From Table 4 we observe an increase for the value of $\alpha_{0}$ with degradation which corresponds to a diminution in the potential energy barrier, $\mathrm{W}_{0}$.

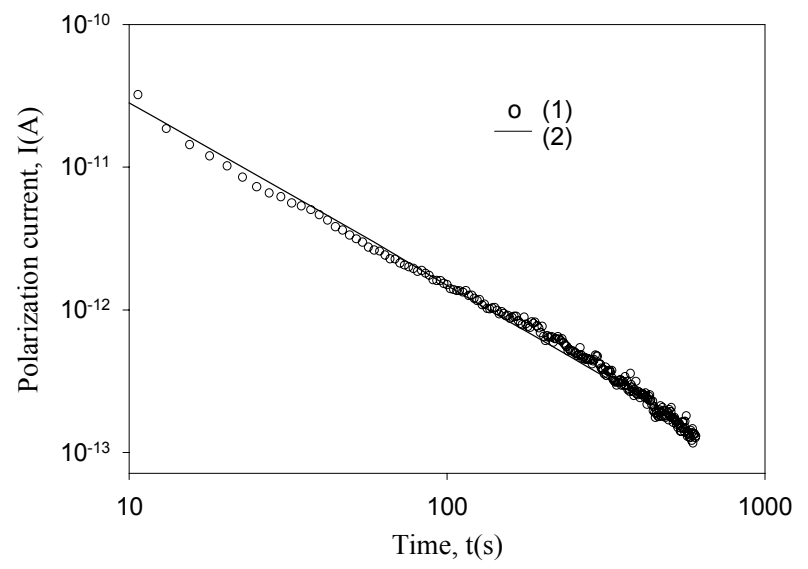

Figure 12. Current results from numerical simulation (2) and from measurements (1) for a LDPE treed sample of degraded width, $\mathrm{g}=70.7 \%$ $\left(\mathrm{t}_{\mathrm{ag}}=250 \mathrm{~h}\right)$ and microscopic parameters: $\tau=0.27 \mathrm{~s}, \alpha_{0}=1.0385 \mathrm{~s}^{-1}, \mathrm{~W}_{0}=0.713$ $\mathrm{eV}$.

\section{DISCUSSION}

The relative permittivity of water trees in LDPE continuously increased from its value for non-degraded PE, $\varepsilon_{2}=2.3$, up to a maximum value $\varepsilon_{1 \max }=4.1$, for an ageing period of $272 \mathrm{~h}$ and an average water tree length of $373 \mu \mathrm{m}$ $(\mathrm{g}=74.6 \%)$; it supplies a permittivity amplification factor $\mathrm{A}_{\varepsilon}=1.8$, a little bit higher than the value found for XLPE in [10], $\mathrm{A}_{\varepsilon}=1.6$. From polarization current measurements we could determine the evolution of coefficients $\left\{\mathrm{I}_{0}, \mathrm{~m}\right\}$ of the Curie-von Schweidler law with the ageing time. A progressive increase was obtained for both coefficients: $9897 \%$ for $\mathrm{I}_{0}$ and $95 \%$ for $\mathrm{m}$, when the degraded width grew from $\mathrm{g}=0 \%$ (new sample) up to $g=70.7 \%$ (sample with a high level of degradation). Otherwise, we could establish, as $\mathrm{V}_{\mathrm{DC}}$ got from $100 \mathrm{~V}$ up to $1000 \mathrm{~V}:\left(\mathrm{I}_{0}\right) 2137 \%$ increase in new samples and $202 \%$ increase in aged samples; (m) $63 \%$ increase in new samples, 25\% decrease in aged samples and, in both cases, it appears a remarkably trend to saturation with $\mathrm{V}_{\mathrm{DC}}$.

\subsection{VARIATIONS OF $\left\{I_{0}, \mathrm{~m}\right\}$ WITH $\mathbf{g}(\%)$}

The diminution of energy barrier $\mathrm{W}_{0}$ with degradation is a consequence of the increasing facility in the movement of charge carriers, which is due to the destruction of the internal structure of the polymer known as "water treeing" [2,4,35]. The increase of $\alpha_{0}$ as an effect of the diminution of $\mathrm{W}_{0}$ is given by equation (4). Then, if equations (14) are supposed to be valid in a qualitative sense for the case of a water-treed material, the increase of $\alpha_{0}$ explains the increasing dependence of $\mathrm{I}_{0}$ and $\mathrm{m}$ with degradation (Figure 6, Table 2 and Table 3 ). Concerning numerical calculations, there was a good agreement between measurements and simulation results of polarization currents in aged samples for ageing periods: $34 \mathrm{~h}$, $64 \mathrm{~h}, 146 \mathrm{~h}$ and $250 \mathrm{~h}$ (Figure 12).

\subsection{VARIATIONS OF $\left\{\mathrm{I}_{0}, \mathrm{~m}\right\}$ WITH $\mathrm{V}_{\mathrm{DC}}$}

( $\left.\mathbf{I}_{\mathbf{0}}\right)$ From equation (14ii) we consider that, basically, parameter $\mathrm{I}_{0}$ is linearly dependent on $\mathrm{V}_{\mathrm{DC}}$ (i.e. dependencies on $\mathrm{V}_{\mathrm{DC}}$ through parameters $\alpha_{0}$ and $\tau$ are supposed to be less important or irrelevant). Consequently $\mathrm{I}_{0}$ should increase with $\mathrm{V}_{\mathrm{DC}}$ both in aged samples -in a qualitative sense- and in new samples -in an analytical sense-, as we found in our current measurements (see Table 3, Figure 8).

(m) New samples: From equation (14i) we can explain the enhanced values of $m$ as $V_{D C}$ grows (Table 3 -Series $M-$, Figure 9) if we show the physical reason for the decrease of $\mathrm{W}_{0}$ with $\mathrm{V}_{\mathrm{DC}}$ : a higher applied voltage, $\mathrm{V}_{\mathrm{DC}}$, produces a higher internal energy of the system which means again an increased facility of movement inside the atomic-molecular system (both for the charge carrier jumps and for the rotations of molecular chains that constitute the polymer). The resultant effect is "just as if" the effective two-wells energy barrier, $\mathrm{W}_{0}$, had a diminution. Naturally and furthermore, the superposition of the curve representing the two wells potential energy to the curve of the applied potential energy (application of $V_{D C}$ ) is equivalent to a physical diminution in the height of the potential energy barrier.

Aged samples: We should emphasize the fact that the more degraded the water treed LDPE, the more inhomogeneous it becomes and a larger number of possible polarization mechanisms it acquires, i.e., the degraded LDPE can adopt a whole spectrum of possible different energy barriers, $\mathrm{W}_{0 \mathrm{i}}$, one for each type of atomic-molecular species involved and/or process of dielectric relaxation. Such different mechanisms are available due to the state of degradation of the polymer but they will only be effective mechanisms -they will be activated- depending on the level of polarization voltage that is applied for each experience. If a higher DC voltage is applied, new polarization mechanisms with a greater barrier height, $\mathrm{W}_{0 \mathrm{i}}$, are activated, which implies from equations $(4,14 \mathrm{i})$ respectively that the corresponding jumping frequencies $\alpha_{0 \mathrm{i}}=2 v \exp \left(-\mathrm{W}_{0 \mathrm{i}} / \mathrm{kT}\right)$ are smaller in these processes and then that the decreasing slopes in the log-log representation, $\mathrm{m}_{\mathrm{i}}$, are smaller. The incorporation of those new mechanisms results in an average slope, $\mathrm{m}$, that diminishes as $\mathrm{V}_{\mathrm{DC}}$ grows (see Table 3 -Series $\mathrm{J}-$, and also have a look at Figures 8-9). Although the process of effective diminution of each particular barrier height with the applied voltage described for new samples also applies to aged samples, it is clear that the effect of activation of greater barriers in aged 
samples due to increasing degradation must be a predominant one.

\subsection{FURTHER CONDUCTION MODELLING}

The new proposed model explains satisfactorily the potential -Curie-von Schweidler- dependence of polarization currents in LDPE specimens new and aged with different degrees of water-tree damage up to a very high percentage degraded width of about $70 \%$. In aged samples, the new model can also account for the variations of parameters $\left\{\mathrm{I}_{0}, \mathrm{~m}\right\}$ as a function of degradation $(\mathrm{g} \%)$ and $\mathrm{I}_{0}$ as a function of polarization voltage. The increase of the water tree thickness seems to diminish the potential energy barrier which is compatible with the increasing values of $\mathrm{I}_{0}$ and decreasing values of $\mathrm{W}_{0}$ from Tables 2, 3 and 4. The explanations for the variations of exponent $\mathrm{m}$ as a function of $\mathrm{V}_{\mathrm{DC}}$ are much more controversial as discussed in previous section and need more clarification.

In new samples, experimental current measurements show exponents $\mathrm{m}<1$ and then our model (see equation 14.i) cannot explain them, therefore other models should be revised $[36,37,38]$ and even an experimental study as a function of temperature would be of interest to confirm the predicted temperature dependences in equations 14 .

In order to elaborate more detailed models of polarization currents in PE it is necessary to incorporate the thermoelectrical degradation mechanisms to simulations. These mechanisms should take into account the processes of space charge accumulation, charge transport and the distributions and concentrations of trapping centers [39]. Recent investigations ("ARTEMIS" European project $[14,40]$ ) have already characterized PE insulation by using "ageing markers". This characterization is performed by means of sophisticated experimental techniques (PEA, FTIR, SEM, TEM, TSM, DEA, DSC,...), some of which our research group has also begin to use. These studies will have many industrial applications for cable manufacturers and power distribution utilities. Particularly, the development of underground extra high voltage XLPE cables (EHV: 400-500 kV) where electric field is approximately, $\mathrm{E} \sim 16 \mathrm{kV} / \mathrm{mm}$, quite higher than electric field in traditional moderately-stressed power cables, E 6 $\mathrm{kV} / \mathrm{mm}$. Secondly, the development of "robust" diagnostic technologies which would also serve to evaluate and improve the reliability of traditional power cables that have been in service for about 30 years. This is of outstanding relevance for distribution companies in the present deregulated market, where utilities are "fiercely" competing for offering clients a more reliable and non-expensive product.

\section{CONCLUSIONS}

Accelerated-aged LDPE specimens with different levels of water tree degradation were characterized by means of measurements of water tree kinetics, capacitance and polarization current. Combining water tree kinetics and capacitance measurements, the maximum average value for the relative permittivity of water trees in LDPE was calculated, $\varepsilon_{1 \max }=4.1$. Polarization current measurements were fitted to the potential Curie-von Schweidler law in order to study the evolution of its parameters $\left\{\mathrm{I}_{0}, \mathrm{~m}\right\}$ with ageing time and polarization voltage.

An interpretation of the experimental results has been given from a new conduction model in LDPE that takes into account dipole interactions and was obtained from a modification of a previously published two-wells Debye model. The proposed model provides easy analytical expressions for the dependencies of the experimental Curie-von Schweidler parameters on both microscopic and macroscopic variables of the LDPE plane-plane samples under test. From the evolution of these variables with water tree degradation width, $g(\%)$, and polarization voltage, $\mathrm{V}_{\mathrm{DC}}$, we could simulate polarization currents that had a good deal of accord to measurements in accelerated-aged LDPE specimens.

This work represents a contribution to improve the knowledge of conductive processes in water-tree degraded polyethylene which can certainly allow a better characterization of power cable insulation under service conditions.

\section{ACKNOWLEDGMENT}

Authors are grateful to industrial partners GENERAL CABLE (Manlleu-Barcelona, Spain) -cable manufacturer- and Sevillana-ENDESA (Sevilla, Spain) -distribution utility- for supplying cable samples and collaboration during the period of development of the present work.

\section{REFERENCES}

[1] L. A. Dissado and J.C. Fothergill, Electrical Degradation and Breakdown in Polymers, ed. G.C. Stevens P. Peregrinus for IEE London, U.K. (ISBN 086341186 7), 1992.

[2] E.F. Steennis and F.H. Kreuger, "Water treeing in polyethylene power cables", IEEE Trans. Electr. Insul., Vol. 25, pp. 989-1028, 1990.

[3] I. Radu, P. Notingher and J.C. Filippini, "The influence of an individual water tree on the electric field distribution in point-point geometry", J. Electrostatics, Vol. 48 (3-4), pp. 165-178, 2000.

[4] M. Acedo, "Relations between the water tree degradation of polyethylene and the electrical properties of the material. Application to the insulation diagnostics of power cables". PhD Thesis, University of Sevilla, 2004.

[5] J.L. Chen and J.C. Filippini, "The Morphology and Behavior of the Water Tree", IEEE Trans. Electr. Insul., Vol. 28, pp.271-286, 1993.

[6] M. Acedo, I. Radu, F. Frutos, J.C. Filippini and P. Notingher, "Water Trees in Underground MV Cables: Modelling and Electric Field Perturbation", J. Electrostatics, 53 (4), pp. 267-294, 2001.

[7] I. Radu, "Electric field calculation and the influence of water trees on insulation breakdown in needle-plane geometry", J. Electrostatics, Vol. 60, pp. 49-67, 2004.

[8] M. Acedo, F. Frutos, M. Torres and J.C. Filippini, "The Cylindrical Capacitive Model for Water Treeing Degradation in Extruded HV Cables", 5th International Conference on Conduction and Breakdown in Solid Dielectrics, Leicester, IEEE Publication 95CH3476-9, pp. 661666, 1995.

[9] L.A. Dissado, "Predicting Electrical Breakdown in Polymeric Insulators", IEEE Trans. Dielectr. Electr. Insul., Vol. 9, pp. 860-875, 2002.

[10] I. Radu, M. Acedo, J.C. Filippini, P. Notingher and F. Frutos, "Influence of Water Trees on the Electric Field Distribution in XLPE and its Consequences on Insulation Dielectric Strength", IEEE Trans. Dielectr. Electr. Insul., Vol. 7, pp. 860-868, 2000. 
[11] J.M. Urtubi, G. Reolid, J. Sarda and F. Valls, "The behaviour of dry insulation medium voltage cables in a moist environment", Jicable'95, pp. 366-369, 1995.

[12] M.A. Dakka, A. Bulinski and S. Bamji, "Correlation between DC polarization and failure characteristics of XLPE and EPR aged with AC voltage in a wet environement", IEEE Trans. Dielectr. Electr. Insul., Vol. 12, pp. 700-708, 2005.

[13] J.N. Marat-Mendes, R.M. Neagu and E.R. Neagu, "Electrical conduction and space charge trapping in highly insulating materials", J. Phys. D: Appl. Phys. Vol. 37, pp.343-347, 2004.

[14] J.C. Fothergill, G.C. Montanari, G.C. Stevens, C. Laurent, G. Teyssedre, L.A. Dissado, U.H. Nilsson and G. Platbrood, "Electrical, microstructural, physical and chemical characterization of $\mathrm{HV}$ cable Peelings for an electrical aging diagnostic data base", IEEE Trans. Electr. Insul., Vol 10 , pp. 514-527, 2003.

[15] T. Heizmann and W.S. Zaengl: "A Novel Diagnostic Method for Buried Polymer-Insulated Medium Voltage Cables"; $8^{\text {th }}$ Int. Symp. on High Voltage Engineering, Ypkohama, Japan, 1993, pp. 185-188, paper 67.04.

[16] B. Oyegoke, P. Hyvonen, M. Aro and N. Gao, "Application of Dielectric Response Measurement on Power Cable Systems", IEEE Trans. Dielectr. Electr. Insul., Vol.10, pp.862-873, 2003.

[17] P. Werelius, P. Thärning, R. Erikson, B. Holmgren and U. Gäfvert, "Dielectric Spectroscopy for Diagnosis of Water Tree Deterioration in XLPE Cables”, IEEE Trans. Dielectr. Electr. Insul., Vol.8, pp.27-42, 2001.

[18] R. Fournié, "Les isolants en électrotechnique. Concepts et théories", Chapitre 5, Editions Eyrolles, 1986.

[19] A. Helgeson and U. Gäfvert, "Dielectric response measurements in time and frequency domain on high voltage insulation with different response". Proceedings of 1998 Symposium on Electrical Insulation Materials, in conjunction with 1998 Asian International Conference on Dielectrics and Electrical Insulation and the $30^{\text {th }}$ Symposium on Electrical Insulating Materials, Toyohashi, Japan, pp. 393-398, 1998.

[20] S. Hvidsten, H. Faremo, J.T. Benjaminsen, E. Ildstad, "Condition assessment of water treed service aged XLPE cables by dielectric response measurements", CIGRE paper 21-201, Paris, 2000.

[21] F. Frutos, M. Acedo, A. Jadraque, M. Mudarra, J. Sellarès and J. Belana, "Comparative Study of Conductivity in Mid-Voltage Cable XLPE Insulation", 8th Intern. Conf. Conduction and Breakdown in Solid Dielectrics, Toulouse, (France), pp. 119-122, 2004.

[22] F. Frutos, A. Jiménez and J.A. Pérez, "Numerical simulation of electric currents through insulating materials", 6th Intern. Conf. Conduction and Breakdown in Solid Dielectrics, Västeras, pp. 206-209, 1998.

[23] A.K. Jonscher, Dielectric Relaxation in Solids, Chelsea Dielectric Press, London 1983.

[24] L.A. Dissado and R.M. Hill, "Non exponential decay in dielectrics and dynamics of correlated systems", Nature, Vol. 279, pp. 685-689, 1979.

[25] A.K. Jonscher, "Physical basis of dielectric loss", Nature, Vol. 253, pp.717-719, 1975.

[26] F. Ciuprina, A. Ifrim, P.V. Notingher, G. Marin and J.C. Filippini, "Absorption Current in Irradiated Polyethylene with Water Trees", MmdE'97, Bucharest (Romania), pp. 241-244, 1997.

[27] S.S. Bamji, A.T. Bulinski and Y. Chen, "Thermally Stimulated Current Technique to Evaluate Polymer Degradation due to Water Treeing", IEEE Trans. Electr. Insul., Vol. 28, No. 2, pp. 299-302, 1993.

[28] R. Patsch and P. Romero: "Electrical Signals from Water Trees. Polarization and Depolarization Currents". 6th IEE DMMA, Manchester, U.K., ref no. 55, 1992.

[29] C. Ku and R. Liepins, Electrical Properties of Polymers. Chemical Principles, Chapter 5, pp 223-229. Hanser Publishers, 1987.

[30] I. Radu, M. Acedo, P. Notingher, F. Frutos and J.C. Filippini, "A Study on the Dependence of Water Tree Permittivity with Time", IEEE Conf. Electr. Insul. Dielectric Phenomena, San Francisco (USA), pp. 762-765, 1996.

[31] J.P. Crine and J. Jow, "A Water Treeing Model", Trans. Dielectr. Electr. Insul., Vol. 12, pp. 801-807, 2005

[32] F. Frutos, M. Acedo, I. Radu, A. Jiménez, J.A. Pérez Gómez, J.C. Filippini and A. Jadraque, "A New Approach to the Modelling of the Conduction Processes in a Water Tree Degraded LDPE", 7th Intern. Conf. Conduction and Breakdown in Solid Dielectrics, Eindhoven, pp. $167-170,2001$
[33] R. Bartnikas, R.M. Eichhorn, "Engineering Dielectrics", Vol. IIA, "Electrical properties of Solid Insulating Materials...", ASTM STP 783, Bartnikas/Eichhorn, Eds., American Society for Testing and Materials, Philadelphia, 1983.

[34] M. Acedo, I. Radu, F. Frutos, J.C. Filippini, A. Jiménez, J.A. PérezGómez and A. Jadraque, "The Characterization of a LDPE Affected by Different Levels of Water Tree Degradation using Absorption Current Measurements", 7th Intern. Conf. Conduction and Breakdown in Solid Dielectrics, Eindhoven, pp. 508-511, 2001.

[35] R. Ross and J.J. Smit, "Composition and Growth of Water Trees in XLPE, IEEE Trans. Electr. Insul., Vol. 27, pp. 519-531, 1992.

[36] Advances in Chemical Physics (Dynamical Processes in Condensed Matter), Vol. 63 Ed. Myron W. Evans, chapter 3, pp. 253-292, 1985.

[37] J. Bernasconi, H.U. Beyeler, S. Strassler and S. Alexander, "Anomalous Frequency-Dependent Conductivity in Disordered One-Dimensional Systems", Phys. Rev. Lett. Vol. 42, pp. 819-822, 1979

[38] H. Sher and E.W. Montroll, "Anomalous transit-time dispersion in amorphous solids", Phys. Rev. B, Vol. 12, pp. 2455-2477, 1975.

[39] I. Tamayo, J. Belana, J.A. Diego, J.C. Cañadas, M. Mudarra and J. Sellarés, "Space charge studies of crosslinked polyethylene midvoltage cable insulation by stimulated depolarization current, infrared/Fourier transform infrared, and scanning electron microscopy", J. Pol Sci Part B Pol Phys Vol 42, 4164-4174, 2004.

[40] H. Herman, J. Thomas and G. Stevens, "Spectroscopic and chemometrics analysis of cable condition in the Artemis program", $8^{\text {th }}$ Intern. Conf. Conduction and Breakdown in Solid Dielectrics, Toulouse, France, pp. 623-627, 2004.

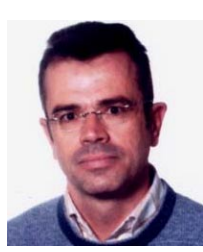

Miguel Acedo García was born in Córdoba (Spain) in 1963. He graduated with B.Sc. (1986, Physics "Licenciado"), M.Sc. (1988, microelectronics) and Ph.D. (2004, electrical engineering) degrees from the University of Sevilla. In the last few years he has been active in the study of electrical and ageing properties of solid insulating materials (especially polyethylene), particularly in the diagnostics of power cables affected by water treeing. He has participated in several European research projects in cooperation with the "Laboratoire d'Electrostatique et Matériaux Diélectriques", LEMD-CNRS (Grenoble, France), involving universities, distribution utilities and manufacturers of cables. He was awarded the "Doctorado Europeo" degree in 2004 and is currently Profesor Titular EU at the ETS Ingeniería Informática (Univ. Sevilla).

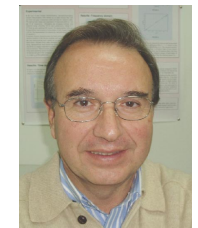

Fabián Frutos Rayego was born in Sevilla (Spain) in 1948. He graduated in Physics (B.Sc., 1973) and obtained the Ph.D. (1987) degree from the University of Sevilla. In the last few years his research interest has been focussed on the study of the electrical properties of solid insulating materials, particularly the diagnostic of power cables degraded by water trees, the effect of annealing on polymeric insulation and the electrical characterization of dielectric-oxides thin films prepared by IBICVD and PECVD. Presently he is Catedrático EU at the ETS Ingeniería Informática (Univ. Sevilla).

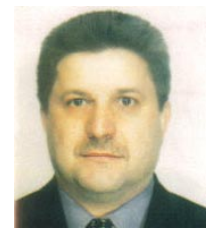

Ion Radu was born in Goruna, Prahova, Romania. He received the B.Sc. and Ph.D. degrees from the Politehnica University of Bucharest, Romania, in 1988 and 1997, respectively. He worked as a research scientist at the French CNRS, "Laboratoire d'Electrostatique et Matériaux Diélectriques" (LEMD) (1994-1998), and at the "Laboratoire d'Electrotechnique" (1999), both in Grenoble, France. He was a lecturer at the Politehnica University (19901999), and an invited professor at the Facultad de Informática, Universidad de Sevilla, Spain (1999). He was Research Associate and Lecturer at the École Polytechnique de Montréal (2000-2004) and since 2004 he is project leader in Research Department at CTT Group and lecturer at the Electrical Department of the École Polytechnique de Montréal. He has authored or coauthored more than 80 publications (journal articles and international communications), has coedited one book and has 2 patents. His major research interests are high voltage engineering, the physics and applications of dielectrics and electrical insulation, atmospheric and low pressure plasmas and numerical methods of computation. 
Jean César Filippini was born in Calvi, Corsica in 1939.

$\mathrm{He}$ received the degree of electrical engineer from the

Polytechnical Institute of Grenoble, France in 1964. He

went to scientific research at CNRS in 1965 and received the Ph.D. degree in physics in 1972 from the Joseph Fourier University. He has made a career of research in physics at the Laboratory for Electrostatics and Dielectric

Phenomena of CNRS in Grenoble. His main subjects of research have been electrical conduction in insulating liquids and electrohydrodynamics, electrooptics in polar liquids, pretransitional phenomena in liquid crystals, water treeing in cable insulation. He is presently working on ageing and conduction phenomena in polymers. 